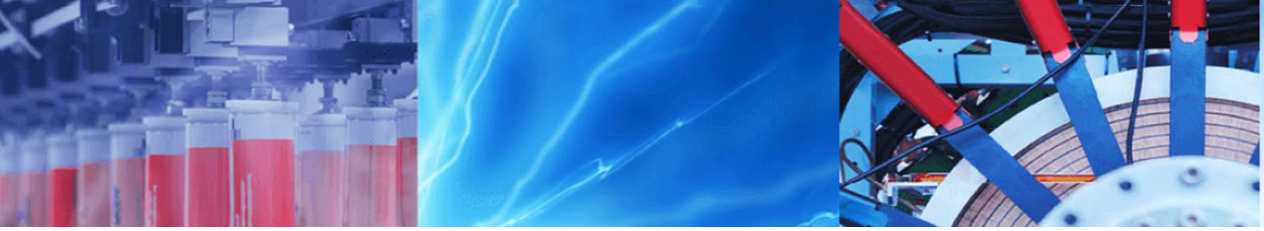

Research Article

\title{
Synthesis of calcium based nano powders for application in conservation and restoration of heritage mortar
}

\author{
Dipak Kr. Chanda ${ }^{1}$. Prosenjit Khan ${ }^{1} \cdot$ Nitai Dey $^{1} \cdot$ Mousumi Majumder $^{2} \cdot$ Ashim K. Chakraborty $^{2}$. \\ Bharat Bhushan Jha ${ }^{1}$. Jiten Ghosh ${ }^{1}$ (D)
}

Received: 14 August 2019 / Accepted: 30 January 2020 / Published online: 4 February 2020

(c) Springer Nature Switzerland AG 2020

\begin{abstract}
In recent years, nano calcium hydroxide $(\mathrm{NCH})$ finds its potential applications in conservation and restoration of heritage structures due to its improved surface treatment. In the present study hexagonal NCH powders were synthesized for surface treatment of heritage mortar. Lime is usually adopted for the conservation of surface treatment due to quick transformation of lime into calcium carbonate. However the incomplete lime carbonation process and reduced penetration depth are the undesired limits for the surface treatment. Present work will report the chemical stability and mechanical behavior before and after surface treatment using this synthesized $\mathrm{NCH}$ powder in heritage mortar. For this purpose, morphologically tuned Calcium hydroxide nono powders were characterized by X-ray diffraction (XRD), field emission scanning electron microscopy (FESEM), Fourier transform infrared spectroscopy and energy dispersive $\mathrm{X}$-ray analysis (EDAX). For the restoration purpose mortar samples of the heritage building were collected and treated with synthesized NCH powder. The untreated and treated mortar samples were again characterized by XRD, FESEM, EDAX, nano indentation techniques, mercury intrusion porosimetry and thermal expansion coefficient (TEC). The results showed regular hexagonal shaped layered nanoparticles with dimensions about 100-200 nm. These nano particles have pure crystalline features and a high reactivity in terms of the carbonation process. FESEM and EDAX line mapping were performed on the treated mortar sample to evaluate penetration depth and grain adhesion of the nanopowders with treated sample. It was also observed that TEC was decreasing after treatment of synthesized NCH powder which revealed that the mortar under goes shrinkage due to volume decrease of the nano $\mathrm{Ca}(\mathrm{OH})_{2}$ phase.
\end{abstract}

Keywords Nano calcium hydroxide $(\mathrm{NCH}) \cdot$ Conservation $\cdot$ Mechanical behavior $\cdot$ Heritage building

\section{Introduction}

The nanostructured Calcium hydroxide $(\mathrm{Ca}(\mathrm{OH}) 2)$ finds a potential applications in chemical, industrial, environmental, and architectural applications [1-8] due to its high surface to volume ratio. Now a days, nanomaterials are being applied for the repairing work of heritage buildings for improving the consolidation and protection treatments of damage building materials [9-11]. The application of nanotechnology helped to design consolidate products which are compatible with original stone structure. Selection of nanomaterial for the conservation of heritage buildings depends on the physical and chemical properties of stone, degradation mechanism and environmental factors. Calcium hydroxide powders are usually adopted for surface treatment of heritage mortar due to its fast transformation into chemically stable calcium carbonate $[12,13]$. Present study considered nano calcium hydroxide

\footnotetext{
$\triangle$ Jiten Ghosh, jiten@cgcri.res.in | ${ }^{1}$ Advanced Mechanical and Material Characterization Division, CSIR-Central Glass and Ceramic Research Institute, Kolkata 700032, India. ${ }^{2}$ Materials Characterization and Instrumentation Division, CSIR-Central Glass and Ceramic Research Institute, Kolkata 700032, India.
} 
powders due to deep penetration into damaged zones, high reactivity and fast reactions such as carbonation, in the treated zones [14]. Nanolime products are attractive choice mainly for the consolidation of substrates containing calcite considering the intended chemical compatibility between the treated substrate and the treatment product $[3,4]$.

In the present work we reported, the synthesis of the hexagonal layered calcium hydroxide nanoparticles structure in water medium and the probable application of synthesized nanoparticles for the restoration of heritage buildings. The nanoparticles were synthesized by a cost effective environmental friendly method that allows obtaining them easily and drastically reducing the time of synthesis with respect to other procedures reported in literature [15-17]. The straight forwardness and quickness of our synthesis method could allow to scale-up the nanolime production opening different possibilities in engineering fields, where the use of lime play a fundamental role $[18,19]$. This layer nano calcium hydroxide powder showed better mechanical property due to its multilayers structures [20]. The suitability and effectiveness of the surface treatment by this nanopowder has been checked with respect to chemical compositions, mechanical properties, thermal expansion coefficients and porosity. For this purpose, nano calcium hydroxide powders (untreated) and treated mortar samples (after treatment with nano calcium hydroxide powders) were characterized by XRD, FESEM, EDAX, nano indentation (NI) techniques, mercury intrusion porosimetry (MIP) and thermal expansion coefficient (TEC). The aim of this work is to explore the potentiality of the calcium hydroxide nano powders for application in restoration and conservation of heritage structures.

\section{Experimental}

In the present work commercially available reagents were used in the as received condition without any further purification. At first $0.3(\mathrm{M}) 100 \mathrm{~mL}$ solution of $\mathrm{Ca}\left(\mathrm{NO}_{3}\right)_{2}$ $(\mathrm{pH}=9.16)$ was taken in a beaker under continuous stirring at $1200 \mathrm{rpm} .50 \mathrm{ml} 0.001$ (M) CTAB was added in solution as a surfactant. Then 0.3 (M) $200 \mathrm{~mL} \mathrm{NaOH}$ solution $(\mathrm{pH}=13.3)$ was added at once into the $\mathrm{Ca}\left(\mathrm{NO}_{3}\right)_{2}$ solution to avoid carbonation.

Immediately after addition of precipitator $(\mathrm{NaOH}$ solution), the reaction medium became turbid to white. After complete precipitation had been carried out for about 30 min, reaction mixture was taken out and centrifuged (REMI R-24, $8000 \mathrm{rpm}, 5 \mathrm{~min}$ ). The supernatant liquid was rejected. The white solid obtained was washed by DI water for several times to remove the trace of $\mathrm{NaNO}_{3}$. After that the solid obtained was dried in an air oven at $85^{\circ} \mathrm{C}$ for $1 \mathrm{~h}$ in air oven.

The synthesized powder was characterized by X-ray diffraction (XRD) using Rietveld technique, Surface area was measured by BET (Brunauer-Emmett-Teller) method, microstructures were evaluated by field emission scanning electron microscopy (FESEM) and composition of the elements were carried out by energy dispersive $\mathrm{X}$-ray analysis (EDAX) method and Fourier transform infrared (FTIR) spectroscopy.

The XRD studies were carried out in a diffractometer using $\mathrm{Cu}-\mathrm{K}_{\mathrm{a} 1}$ radiation. (Rigaku, Ultima IV, X-Ray diffractometer). The machine was operated at $40 \mathrm{kV}$ and $30 \mathrm{~mA}$. The XRD data were recorded with a step size of $0.02^{\circ}(2 \theta)$ and step time of $3 \mathrm{~s}$ from $10^{\circ}$ to $80^{\circ}(2 \theta)$. The crystallite size and average lattice strain of the synthesized powder were estimated from the XRD line profile analysis using Rietveld analysis [21] by X'part high score plus software. The Rietveld method is a non-linear least square fitting based full-pattern fit method $[22,23]$ for estimation of wt $\%$ phases, values of lattice parameters, average crystallite size and lattice strain of the existing crystalline phases.

Surface areas and pore size distributions of the powder were evaluated by studying the corresponding nitrogen adsorption-desorption isotherms at $-77 \mathrm{~K}$ at relative pressures $\left(\mathrm{p} / \mathrm{p}_{0}\right)$ of $0.10-0.99$ using Quantachrome instrument (version 10.01, ASIQ MP, USA). Surface areas of the powders were measured by BET (Brunauer-Emmett-Teller) method using the adsorbed amount of $\mathrm{N}_{2}$ employed at the desorption of the isotherm. Total pore volumes were determined from the uptake of $\mathrm{N}_{2}$ at a relative pressure of 0.99 . The out gassing temperature was kept constant at $100{ }^{\circ} \mathrm{C}$ for $12 \mathrm{~h}$. BJH (Barrer-Joyner-Halenda) calculations for pore size distribution were done by utilizing the desorption isotherms. Particle morphology of the synthesized powder was carried out by FESEM (FESEM, Supra VP35, Carl Zeiss, Germany).

The presence of the characteristic functional groups of calcium hydroxide and calcium carbonate in $\mathrm{NCH}$ was investigated at $350-8000 \mathrm{~cm}^{-1}$ by using a conventional Fourier transform infrared (FTIR) spectrophotometer (Perkin Elmer). All spectra were recorded as the averages of 8 scans in transmittance mode.

A suspension of $\mathrm{NCH}$ particles $\left(6.5 \mathrm{~g} \mathrm{~L}^{-1}\right)$ was prepared in water-ethanol medium and then were applied on the small pieces of heritage building (Krishna Chandraji Temple, Kalna Rajbari). This heritage building is located $82 \mathrm{~km}$ from Kolkata (Howrah) on the Bandel-Katwa line on the west bank of the Bhagirathi. The surface of the mortar samples were treated by the $\mathrm{NCH}$-water-ethanol suspension to make a thin (about $5 \mu \mathrm{m}$ ) uniform layer of $\mathrm{NCH}$ particles on the surface of the Mortar sample. Then the untreated and surface treated mortar samples were charecterized by 
XRD, FESEM, EDAX, Thermal expension co-efficient, Mercury Intution Porosimetry (MIP) techniques.

The nanomechanical properties like nanohardness $(H)$, Young's modulus ( $E$ ) and other associated properties of treated and untreated morter samples were evaluated by a nanoindenter. It was equipped with a Berkovich tip. The Berkovich indenter had a tip radius of about $150 \mathrm{~nm}$ and a semi-apex angle of $65.3^{\circ}$. The machine worked according to DIN 50359-1 standard. The depth sensing resolution of the machine was $1 \mathrm{~nm}$. The force sensing resolution of the machine is $0.2 \mathrm{mN}$ [24].

The standard fused quartz sample had a known nanohardness of $9.25 \pm 0.93 \mathrm{GPa}$ and a reduced Young's modulus $\left(E_{\mathrm{r}}\right)$ of $69.6 \pm 3.48 \mathrm{GPa}$. The diamond tip had a Poisson's ratio of 0.07 and Young's modulus of $1140 \mathrm{GPa}$ [25]. The nanohardness and Young's modulus data of the treated and untreated morter samples were measured by Oliver and Pharr $[25,26]$ method.

In the load range of $10-300 \mathrm{mN}$, the nanohardness and Young's modulus were measured by nanoindentation technique applied to nano untreated and surface treated mortar samples. Different loads e.g., 10, 50, 100, and 300 $\mathrm{mN}$ were used for the nanoindentation experiments conducted in a standard nanoindenter (Fischerscope H100XY, Fischer, Switzerland).

At each given value of the applied nanoindentation load (e.g., 10, 50, 100, and $300 \mathrm{mN}$ ) at least 36 nanoindentations (in a $6 \times 6$ array) were made on the unpolished surfaces of the surface treated and untreated samples [27]. The loading time to reach the peak load for any given load was kept at $30 \mathrm{~s}$. The unloading time was also kept the same as the loading time.

The pore size distribution of the untreated and surface treated mortar samples were carried out by mercury intuition method in Quantachrome PoreMaster 60, USA machine and thermal expansion co-efficent was carried out in Netzsch GmbH, DIL402C, Germany.

\section{Results and discussion}

\subsection{XRD analysis}

The XRD pattern of the synthesized powder and the corresponding Rietveld analysis based fits are shown is presented in Fig. 1. This pattern (Fig. 1) most certainly confirmed that the sample contained the hexagonal portlandite $\left[\mathrm{Ca}(\mathrm{OH})_{2}\right]$ phase having space group $\mathrm{p}-3 \mathrm{~m} 1$ (Space Group No: 164, ICDD database code: 01-070$5492)$ as the major phase (91.6\%) and the rhombohedral calcium carbonate $\left[\mathrm{CaCO}_{3}\right]$ phase having space group R-3c (Space Group No: 167, ICDD database code:

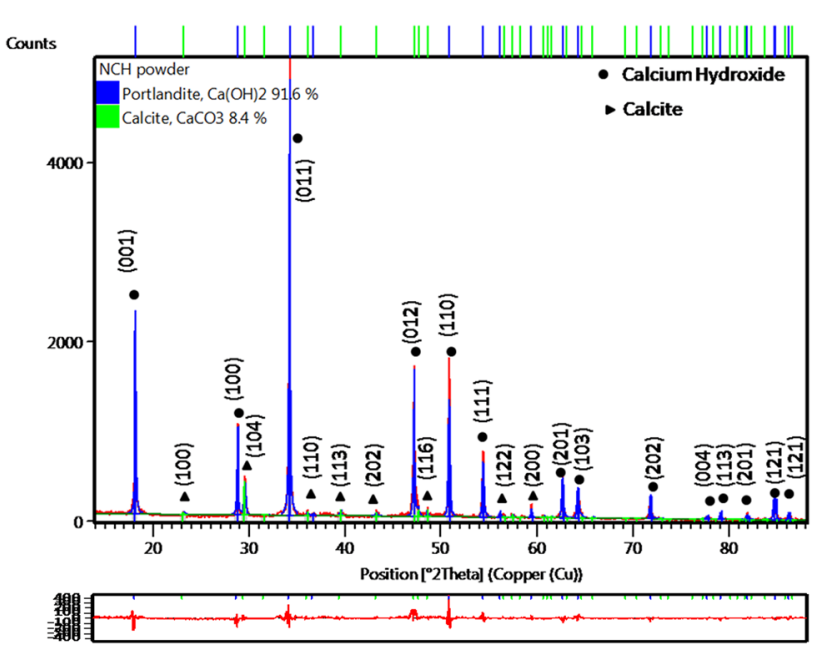

Fig. 1 XRD pattern of synthesized nano calcium hydroxide powder with rietveld analysis

Table 1 Microstructural parameters obtained from rietveld analysis of NCH particles

\begin{tabular}{lll}
\hline Parameters & Portlandite $/ \mathrm{Ca}(\mathrm{OH})_{2}$ & Calcite $/ \mathrm{CaCO}_{3}$ \\
\hline Quantification (wt\%) & 91.6 & 8.4 \\
Crystallite size $(\mathrm{nm})$ & 56.6 & 47.9 \\
Lattice strain $(\%)$ & 0.031 & 0.034 \\
Lattice parameter $(\AA)$ & $\mathrm{a}=\mathrm{b}=3.59694, \mathrm{c}=4.91861$ & $\mathrm{a}=\mathrm{b}=5.00183$ \\
& & $\mathrm{c}=17.04599$ \\
Lattice volume $\left(\AA^{3}\right)$ & 55.08 & 369.13 \\
\hline
\end{tabular}

04-006-6528) as the minor phase (8.4\%). The XRD patterns (Fig. 1) were indexed accordingly. So from XRD pattern, Fig. 1 it is confirmed that in the present work $91.6 \%$ phase pure Nano Calcium Hydroxide powder has been synthesized in water medium.

Based on the XRD pattern presented in Fig. 1, the values of the wt $\%$ of phases, cell parameters, unit cell volumes, average crystallite sizes and average lattice strains were estimated by the Rietveld analysis $[18,19]$. Thus, the results of the Rietveld analysis are shown in Table 1. The XRD pattern of $\mathrm{NCH}$ particle shows the very high crystalline nature of the powder. There is no amorphous nature in synthesized $\mathrm{NCH}$ powder as there is no hump in the $2 \theta$ region $20^{\circ}$ to $40^{\circ}$ (Fig. 1 ).

The crystallite size of the hexagonal $\mathrm{Ca}(\mathrm{OH})_{2}$ (portlandite) phase was $56.6 \mathrm{~nm}$ and corresponding lattice strain $(\varepsilon)$ was $0.031 \%$ (Table 1 ) and the crystallite size of the rhombohedral $\mathrm{CaCO}_{3}$ (calcite) phase was $47.9 \mathrm{~nm}$ and corresponding lattice microstrain $(\varepsilon)$ was $0.034 \%$. The lattice parameters obtained from XRD analysis are given in Table 1. 


\subsection{Surfae area and pore size analysis}

The nitrogen adsorption-desorption isotherm of the sample displayed (Fig. 2a) a type III isotherm and H3 type hysteresis loop according to IUPAC classification indicating the presence of aggregates of plate-like particles giving rise to slit-shaped pores. The appearance of the type $\mathrm{H}-3$ type hysteresis loop at high relative pressures indicated the formation of mesopores among the needle-like and plate-like particles [28]. The surface area of the present powder was measured as $7.93 \mathrm{~m}^{2} / \mathrm{g}$ by the well-known BET method.

As mentioned above, the BJH pore size distributions of the corresponding $\mathrm{NCH}$ particles derived from desorption data of the isotherms are shown in Fig. $2 b$ and a larger view is shown as an inset in Fig. $2 b$. The broader pore size distributions were obtained due to the formation of interparticle as well as interlayer void spaces present in the complex. Total pore volume obtained at $\mathrm{P} / \mathrm{P}_{\mathrm{o}}=0.996416$ was $0.533 \mathrm{ccg}^{-1}$ and average pore diameter obtained from $\mathrm{BJH}$ desorption isotherm was in the range of $20-33 \mathrm{~nm}$.

\subsection{Microstructural analysis}

FESEM photomicrograph of the synthesized NCH particles is shown in Fig. 3a-d. From Fig. 3a, b the presence of aggregates of plate-like particles were confirmed which also corroborated with the result of $\mathrm{N}_{2}$ adsorption desorption isotherm (Fig. 2a). The morphology presented in Fig. 3c confirmed the presence of hexagonal particles. A magnified photomicrograph of hexagonal NCH particle (marked by a circle in Fig. $3 \mathrm{c}$ is shown in Fig. $3 \mathrm{~d}$. The EDAX of the $\mathrm{NCH}$ particle obtained from FESEM were depicted in inset of Fig. 3b. The major elements obtained from EDAX were $\mathrm{Ca}$ and $\mathrm{O}$. Signals from $\mathrm{Mg}, \mathrm{Si}$ and $\mathrm{Al}$ were coming from glass substrate in which the $\mathrm{NCH}$ powder was mounted to perform FESEM characterization.

\section{Characterization of mortar sample (untreated and surface treated)}

\subsection{XRD analysis}

To determine the phases of the untreated and surface treated mortar samples were characterized XRD, Rietveld analysis (Fig. 4a, b).

XRD pattern and Rietveld analysis of the upper surface of untreated and surface treated mortar samples are shown in Fig. $4 a$, $b$ respectively. The composition of the mortar samples before treated with $\mathrm{NCH}$ powder were confirmed from XRD and Rietveld analysis, Fig. 4a and after treated with $\mathrm{NCH}$ powder the XRD pattern and Rietveld analysis graph is shown in Fig. $4 \mathrm{~b}$. The quality of fitting was also assessed from various numerical criteria of fit, namely the profile residual factor $\left(R_{p}\right)$, the expected residual factor $\left(R_{\text {exp }}\right)$, the weight residual factor $\left(R_{w p}\right)$, weighted-statistics $\left(D_{w s}\right)$ and the goodness of fitting (GOF) and has been given in Table 2.

XRD pattern and Rietveld analysis of the upper surface of untreated and surface treated mortar samples are shown in Fig. $4 a$, b respectively. The composition of the mortar samples before and after treated with $\mathrm{NCH}$ powder was confirmed from XRD and Rietveld analysis, Fig. $4 a$, b. The upper surface of untreated mortar sample contain $45.8 \%$ mica, $9.8 \%$ rutile, $12.6 \%$ hematite, $29 \%$ quartz, and $3.2 \%$ calcite. The upper surface of treated mortar sample contain $16.7 \%$ mica, $0.5 \%$ rutile, $13 \%$ hematite, $12.3 \%$ quartz, and $30.1 \%$ calcite and $27.4 \%$ calcium hydroxide. The presence of nano
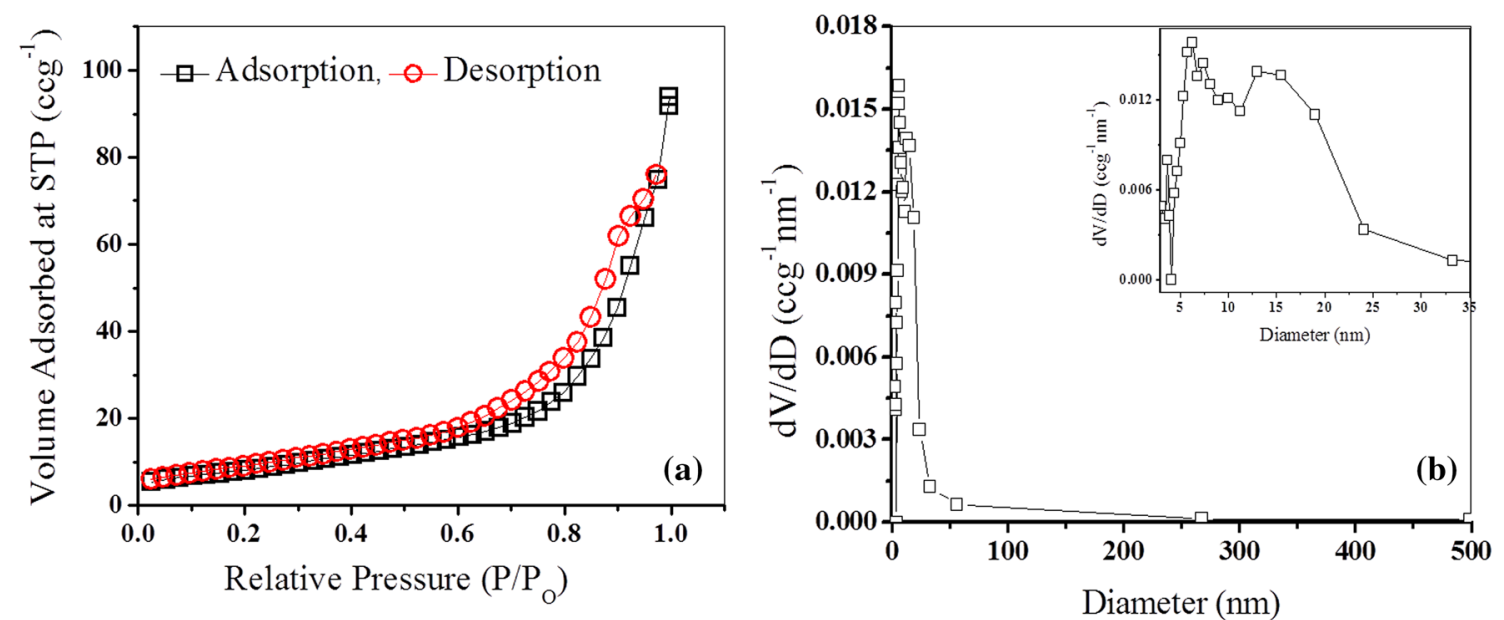

Fig. 2 a $\mathrm{N}_{2}$ adsorption desorption isotherm of NCH particles, b BJH pore size distribution of NCH particles (Inset: magnified version) 

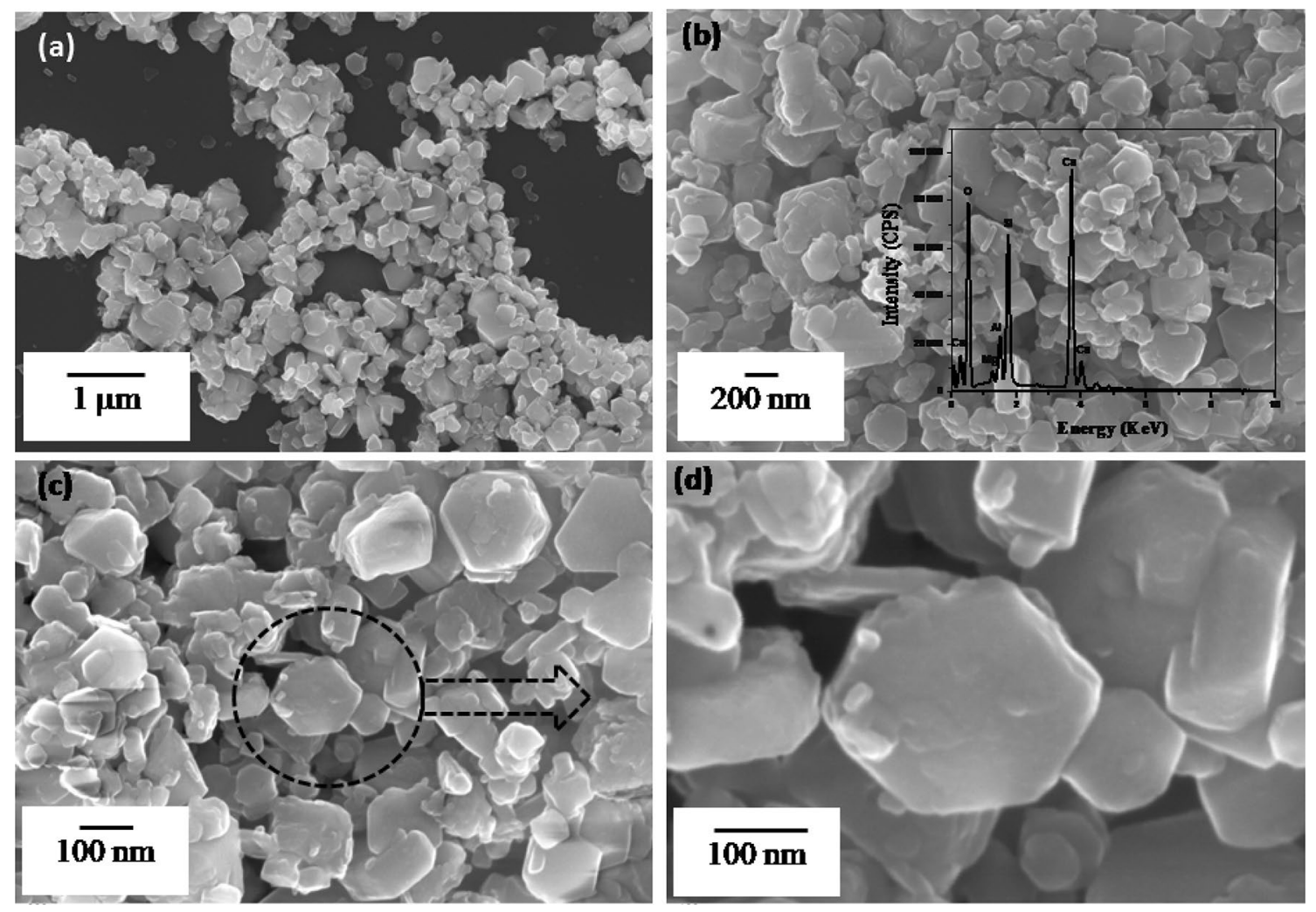

Fig. 3 a-d FESEM photomicrograph of NCH powder, (b inset): EDAX of NCH powder
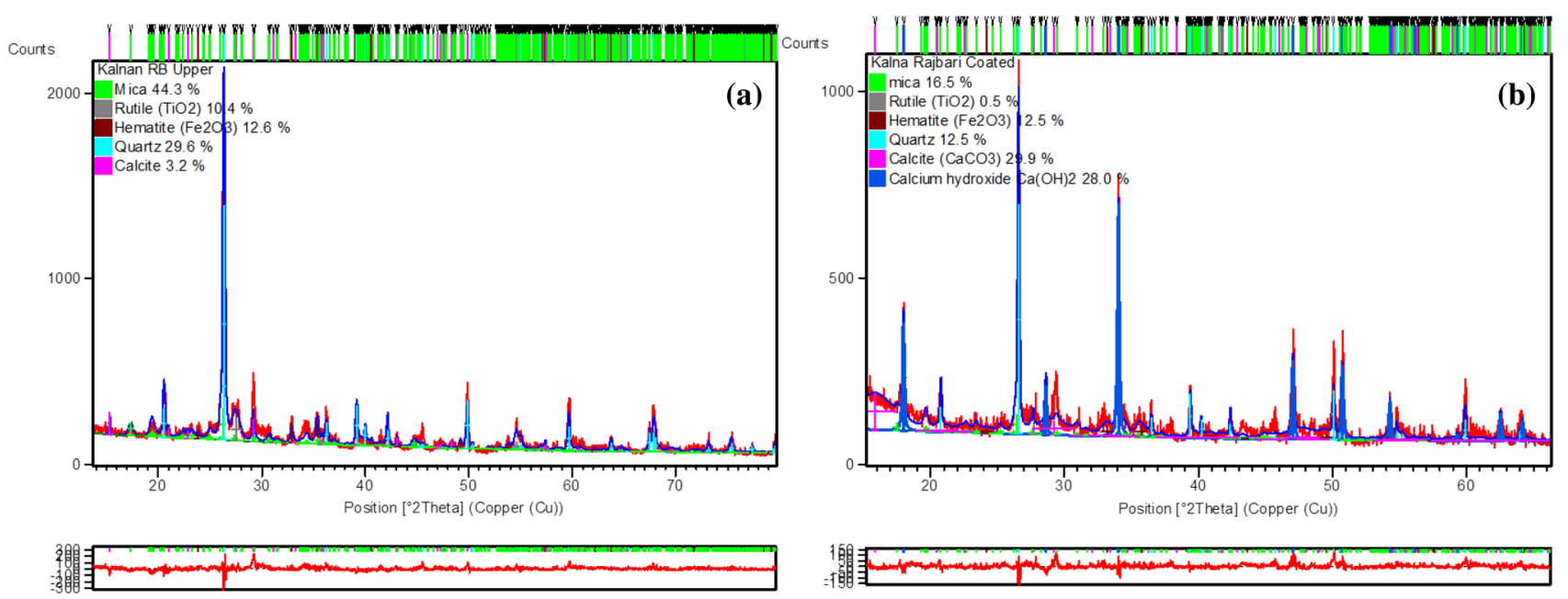

Fig. 4 a, b XRD pattern and Rietveld analysis of untreated Mortar samples and NCH treated mortar samples, respectively

calcium hydroxide on the surface of the treated mortar sample was confirmed from XRD and Rietveld analysis, Fig. $4 \mathrm{~b}$ and the presence of thin layer of calcium hydroxide on the surface of treated mortar probably mask the $\%$ of mica, rutile and quartz. It was further supported by EDAX line profile analysis (Fig. 5c, d). The microstructural parameters of $\mathrm{NCH}$ after treatment are given in Table 3. 
Table 2 The values of relaibality paremeters as obtained by Rietveld analysis

\begin{tabular}{llllll}
\hline Sample & $\mathrm{R}_{\exp }$ & $\mathrm{R}_{\mathrm{p}}$ & $\mathrm{R}_{\mathrm{wp}}$ & $\mathrm{D}_{\text {ws }}$ & $\mathrm{GOF}$ \\
\hline NCH & 13.53826 & 12.8579 & 6.5257 & 1.9202 & 1.49003 \\
Untreated Mortar & 11.7566 & 11.9607 & 15.4211 & 5.41583 & 1.72056 \\
$\begin{array}{l}\text { NCH treated } \\
\quad \text { Mortar }\end{array}$ & 13.11202 & 11.7725 & 15.2007 & 3.44114 & 1.34397 \\
\hline
\end{tabular}

\subsection{Microstructural analysis}

FESEM images of the mortar sample (Fig. 5a), the presence of pores on the surface of mortar sample. Bigger pores are shown by white circle in Fig. 5a. FESEM images of hexagonal NCH treated are shown in Fig. 5b. A lower magnified view of treated sample is shown in the inset of Fig. $5 b$. Form Fig. 5b, it is clear that the pores present in the mortar samples are filled with layered hexagonal NCH particles.

EDAX line mapping and cross sectional FESEM is given in Fig. 5c. From Fig. 5c (inset) it is very clear that the thickness of the NCH coating is about $4.3 \mu \mathrm{m}$.
In EDAX line profile analysis (Fig. 5c, d) the blue color is for Silicon of mortar, green color for Magnesium, red color for oxygen and violet line for Calcium which is coming from NCH coating Fig. 5c, d. From EDAX line profile analysis show that $4.3 \mu \mathrm{m}$ thick $\mathrm{Ca}$ on the surface of the mortar sample is coming due to $\mathrm{NCH}$ coating.

\subsection{Nanomechanical behaviour of untreated and NCH treated mortar samples}

Figure 6a shows the load (P)-depth (h) plots of the untreated mortar sample at different loads (e.g., 10 $\mathrm{mN}, 50 \mathrm{mN}, 100 \mathrm{mN}, 300 \mathrm{mN}$ ). Figure $6 \mathrm{~b}$ showed the

Table 3 Microstructural parameters of $\mathrm{NCH}$ treated mortar sample obtained by Rietveld analysis

\begin{tabular}{ll}
\hline Parameters & $\mathrm{Ca}(\mathrm{OH})_{2}$ after treatment \\
\hline Crystallite size $(\mathrm{nm})$ & 59.16 \\
Lattice strain $(\%)$ & 0.023 \\
Lattice parameter $(\AA)$ & $\mathrm{a}=\mathrm{b}=3.5928, \mathrm{c}=4.9131$ \\
Lattice volume $\left(\AA^{3}\right)$ & 54.92 \\
\hline
\end{tabular}
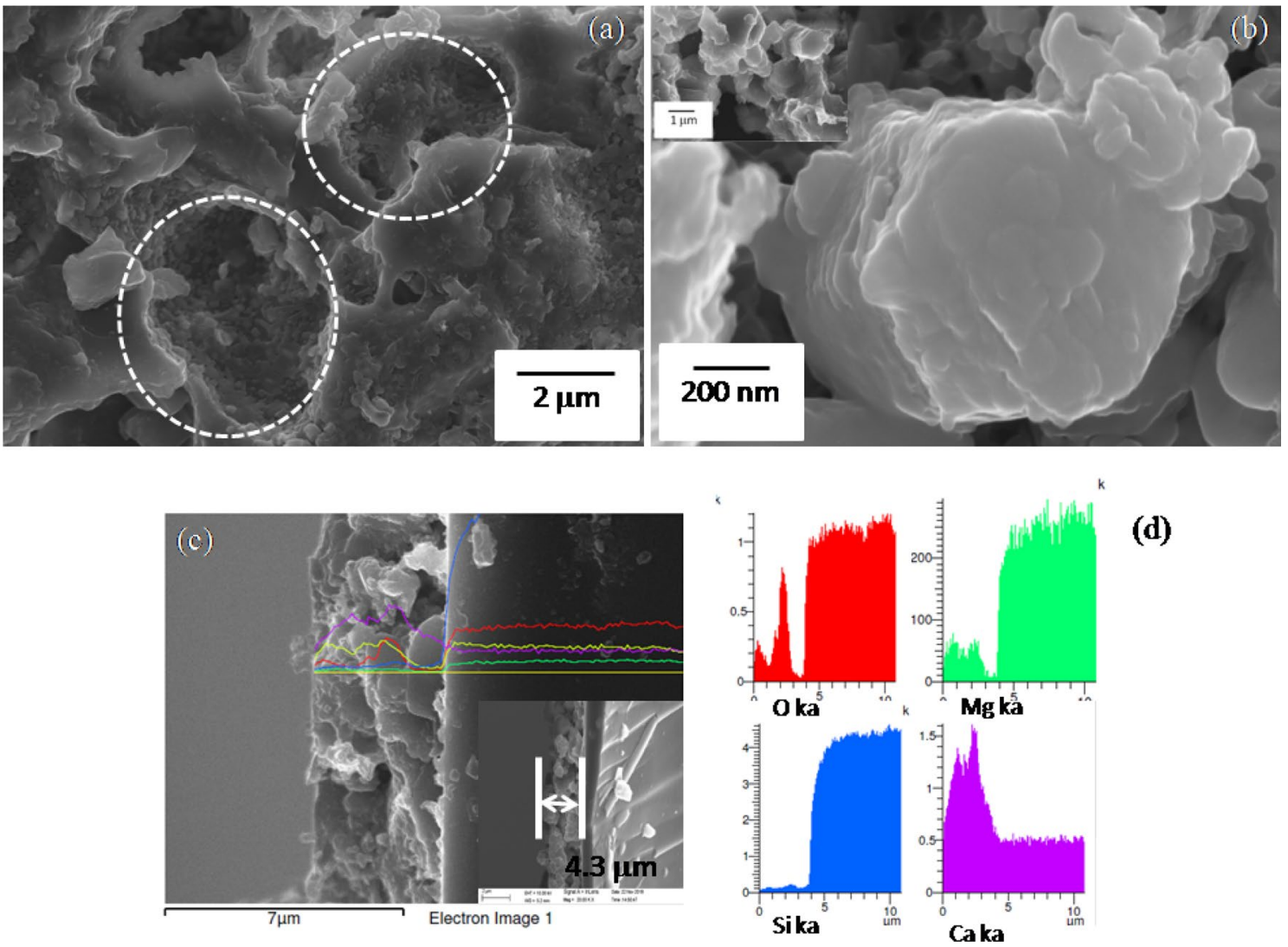

(d)

Fig. 5 a, b FESEM photomicrograph of untreated and NCH treated mortar sample respectively, $\mathbf{c}$, $\mathbf{d}$ crossectional FESEM and EDAX line profile analysis of $\mathrm{NCH}$ treated mortar samples respectively 

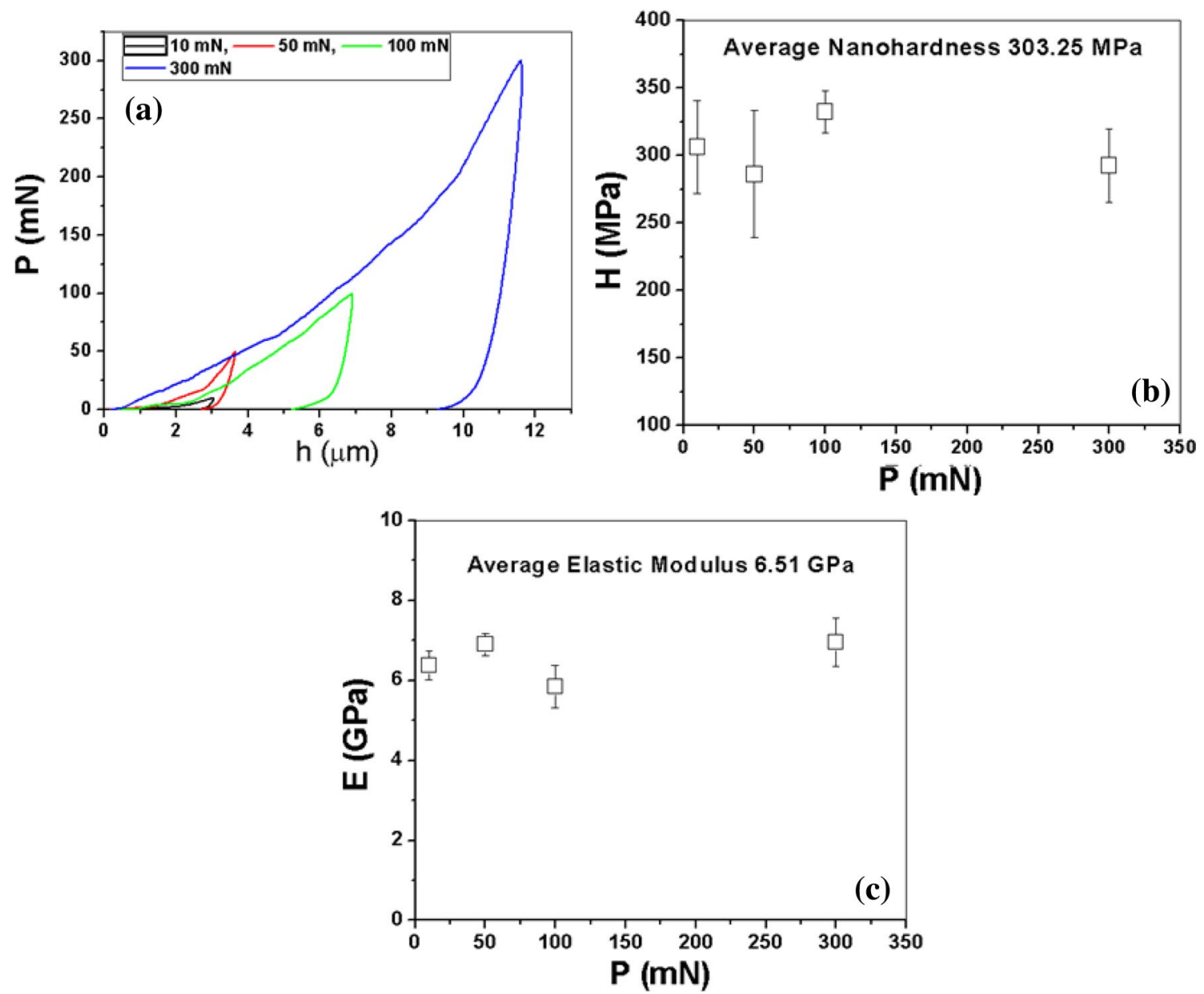

Fig. 6 a Load-depth plot, b variation of nanohardness $(H)$ with load(P), c variation of young's modulus (E) with load of untreated Mortar sample

variation of Nanohardness $(\mathrm{H})$ with applied load $(\mathrm{P})$. Figure $6 c$ showed the variation of Young's modulus $(E)$ with applied load $(P)$. Average nanohardness $(H)$ and Young's modulus (E) of the untreated mortar samples were obtained about $303.25 \mathrm{MPa}$ and $6.51 \mathrm{GPa}$ respectively. Nanohardness $(H)$ and Young's modulus (E) are independent of applied load. This may be due to layer structure of clay materials [20].

Figure 7a shows the load (P)-depth (h) plots of the surface treated mortar sample at different loads (e.g., $10 \mathrm{mN}$, $50 \mathrm{mN}, 100 \mathrm{mN}, 300 \mathrm{mN}$ ). Depth of penetration is higher for untreated sample (Fig. 6a) in compared with surface treated samples, Fig. 7a. This is due to the presence of porous structure of untreated mortar sample (Fig. 5a). Figure $7 b, c$ showed the variation of Nanohardness $(H)$ and Young's modulus $(E)$ respectively, with applied load $(P)$ of the $\mathrm{NCH}$ treated mortar samples. The results showed that Nanohardness $(\mathrm{H})$ and Young's modulus $(\mathrm{E})$ are independent of applied load. This is due to the coating of layered $\mathrm{NCH}$ particles (Fig. 5b). Average nanohardness $(\mathrm{H})$ of $\mathrm{NCH}$ treated mortar sample was obtained about 498.5 MPa and average Young's modulus (E) was obtained about $11.6 \mathrm{GPa}$.

The reason for increment for the values of nanohardness and Young's modulus in $\mathrm{NCH}$ treated mortar than the $\mathrm{NCH}$ has been added in the manuscript. Figure 7 a shows the load (P)-depth $(\mathrm{h})$ plots of the surface treated mortar sample at different loads (e.g., $10 \mathrm{mN}, 50 \mathrm{mN}, 100 \mathrm{mN}, 300$ $\mathrm{mN}$ ). Depth of penetration is higher for untreated sample (Fig. 6a) in compared with surface treated samples, Fig. 7a. This is due to the presence of porous structure of untreated mortar sample (Fig. 5a). Figure 7b, c showed the variation of nanohardness $(\mathrm{H})$ and Young's modulus (E) respectively, with applied load $(\mathrm{P})$ of the $\mathrm{NCH}$ treated mortar samples. The results showed that nanohardness $(H)$ and Young's modulus (E) are independent of applied load. Average nanohardness $(\mathrm{H})$ of $\mathrm{NCH}$ treated mortar sample was obtained about $498.5 \mathrm{MPa}$ and average Young's modulus (E) was obtained about $11.6 \mathrm{GPa}$. This is due to the coating of layered NCH particles (Fig. 5b) [29]. After treatment of $\mathrm{NCH}$ on the Heritage mortar, all the pores were 

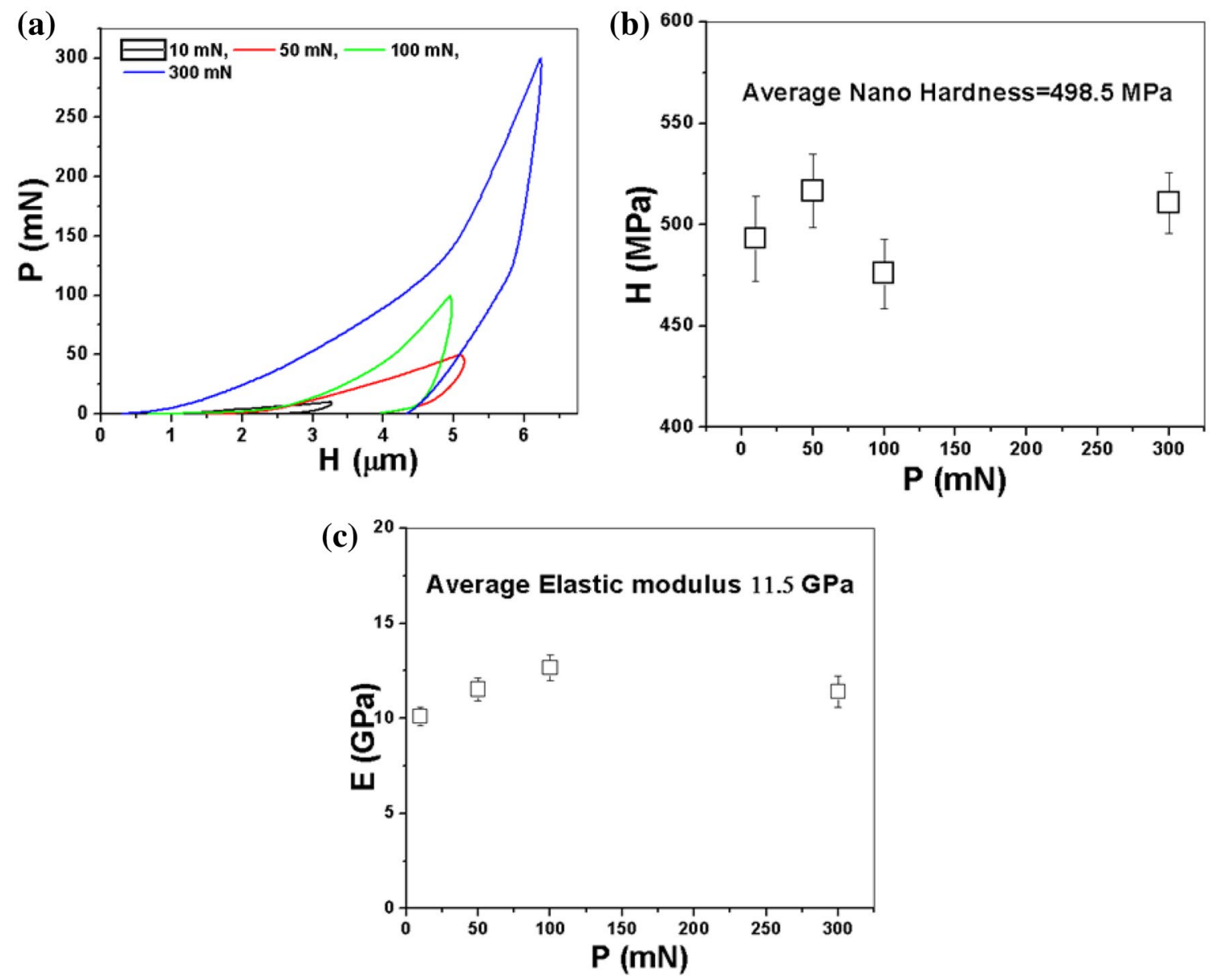

Fig. 7 a Load-depth plot, b variation of nanohardness $(\mathrm{H})$ with load $(\mathrm{P})$, $\mathbf{c}$ variation of young's modulus $(\mathrm{E})$ with load of NCH treated Mortar sample

filled with these nanoparticles and these nanoparticles possess layered structures which leads to the increaemnt of the values of Nanohardness and Youngs modulus in $\mathrm{NCH}$ treated mortar than the untreated mortar.

\subsection{Porosity and thermal expansion co-efficient}

The pore size distributions of untreated and treated samples are shown in Fig. 8a, b. Before and after treatment of $\mathrm{NCH}$ particles total porosity of mortar samples were 74.0968 and $50.1735 \%$ respectively. The pore diameters of the bigger pores were in the range of $1.10 \mu \mathrm{m}$ to $5 \mu \mathrm{m}$ and the small pores were in the range of $0.05 \mu \mathrm{m}$ to $0.24 \mu \mathrm{m}$. After surface treatment of the mortar samples the pores in the range of $1.10 \mu \mathrm{m}$ to $5 \mu \mathrm{m}$ were filled up. Only the small pores in the range of $0.05 \mu \mathrm{m}$ to $0.24 \mu \mathrm{m}$ were open. It is evident that after surface treatment with $\mathrm{NCH}$ the pore structure of the mortar samples reduces. $\mathrm{NCH}$ appears to have filled the pores with larger diameters $(<0.05 \mu \mathrm{m})$ in mortar samples. This may due to better penetration of the $\mathrm{NCH}$ into the larger pores [30].
Thermal expansion co-efficient (TEC) of the mortar samples before and after the surface treatment with $\mathrm{NCH}$ are given in the Fig. $9 \mathrm{a}, \mathrm{b}$ respectively. TEC of the untreated mortar samples were $5.410 \mathrm{e}^{-6 \circ} \mathrm{C}^{-1}$ and that of surface treated samples were $4.509 \mathrm{e}^{-60} \mathrm{C}^{-1}$.

The reason for decreasing the values of thermal coefficients in $\mathrm{NCH}$ treated mortar than the $\mathrm{NCH}$ has been added in the manuscript. It is observed that the thermal co-efficient is decreasing after treatment of the $\mathrm{NCH}$ powder which revealed that the mortar sample under goes shrinkage due to volume decrease of nano $\mathrm{Ca}(\mathrm{OH})_{2}$ phase. From XRD analysis it was observed that unit cell volume of $\mathrm{Ca}(\mathrm{OH})_{2}$ phase $\left(54.92 \AA^{3}\right)$ in treated mortar sample $\left(55.08 \AA^{3}\right.$ ) was less than that of $\mathrm{NCH}$ powder. This result also corroborates with the values of lattice strain as obtain by Rietveld analysis. This leads to the more thermal stability in the $\mathrm{NCH}$ treated samples. So it is very evident that after surface treatment with $\mathrm{NCH}$ particles the TEC values reduced significantly. 


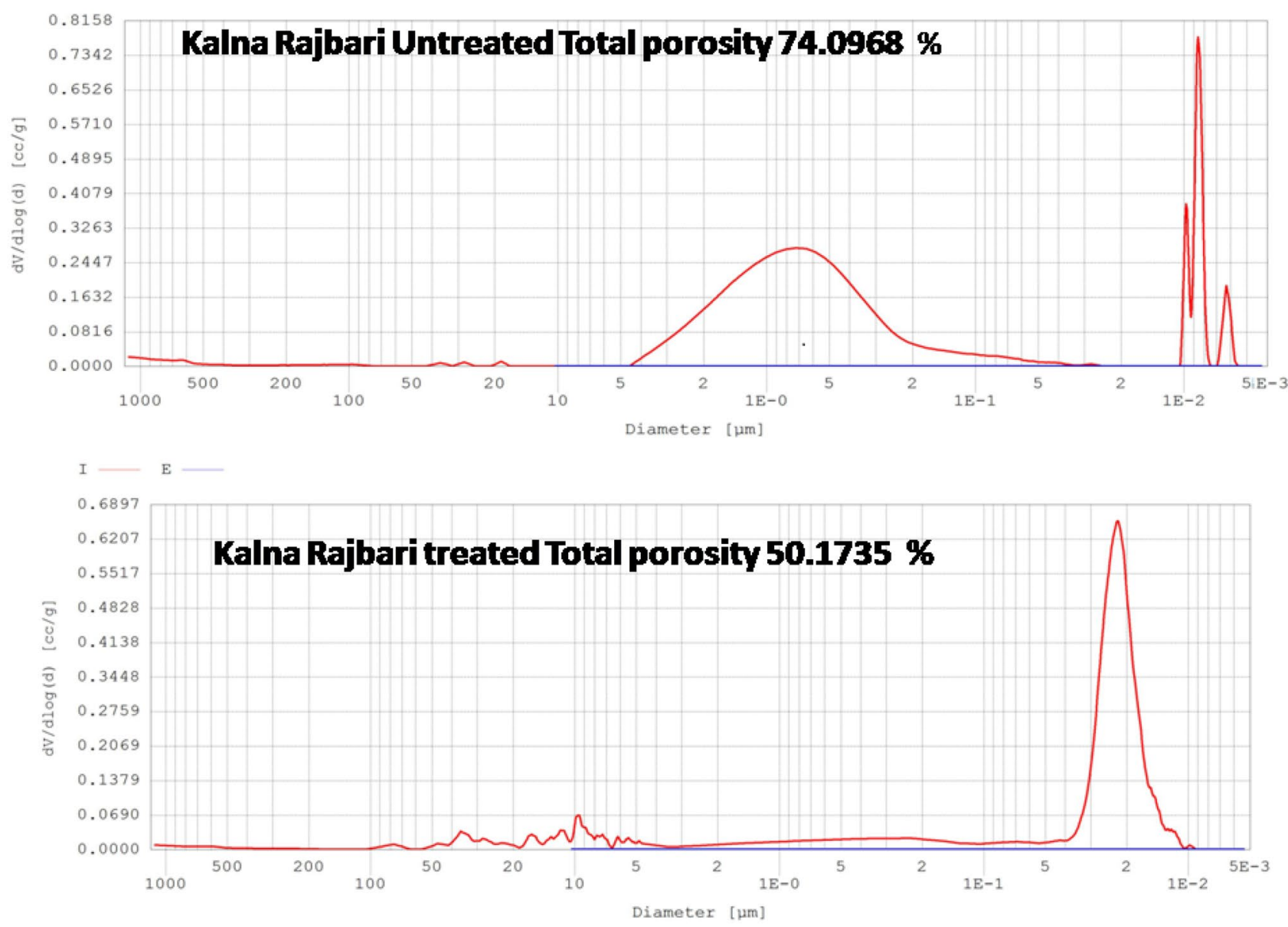

Fig. 8 MIP of $\mathbf{a}$ untreated and $\mathbf{b}$ NCH treated mortar sample
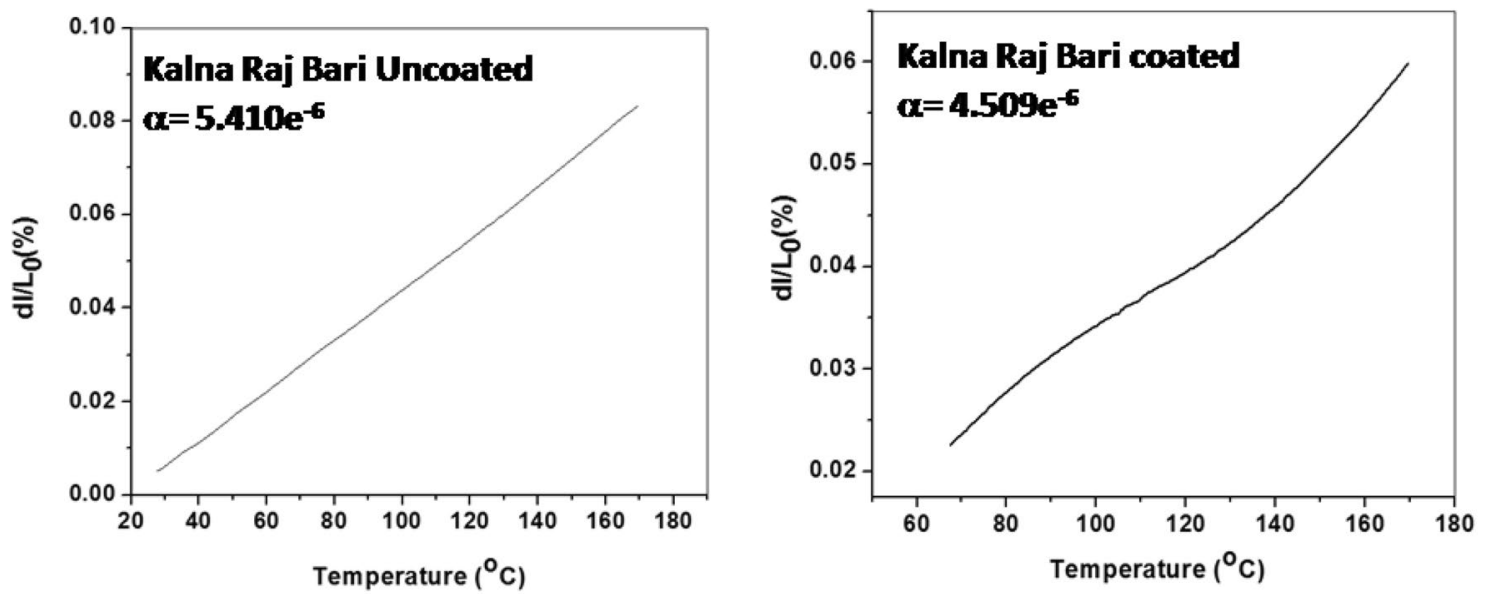

Fig. 9 Thermal expansion co-efficient of $\mathbf{a}$ untreated and $\mathbf{b} \mathrm{NCH}$ treated mortar sample 


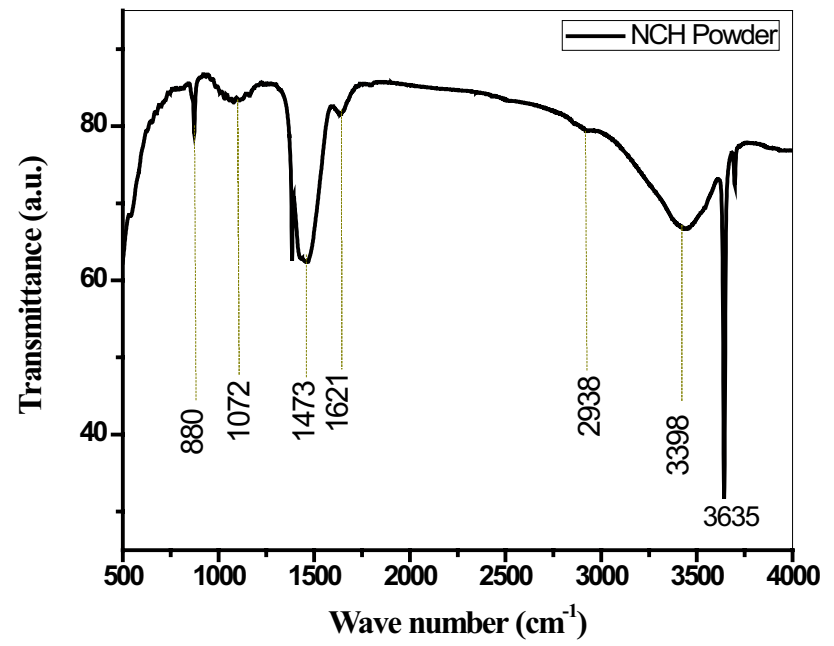

Fig. 10 FTIR spectra of $\mathrm{NCH}$ powder

\subsection{FTIR analysis}

The FTIR spectrum (Fig. 10) of the synthesized powder showed the band characteristics of both calcium hydroxide and calcium carbonate [31]. The relatively strong absorption band at $3635 \mathrm{~cm}^{-1}$ corresponded to the $\mathrm{OH}$ stretching mode.

The $\mathrm{OH}$ stretching absorption band was not so sharp. This fact indicated that instead of pure hexagonal calcium hydroxide phase, a mixture of calcium carbonate phases was formed. Similarly, the broad band from $~ 3250$ to $3560 \mathrm{~cm}^{-1}$, centered at $3398 \mathrm{~cm}^{-1}$ also corresponded to the $\mathrm{OH}$ stretching modes. The sharp peak at $\sim 880 \mathrm{~cm}^{-1}$ corresponded to the symmetric deformation of the carbonate group [11]. The broad band centered at $\sim 1473 \mathrm{~cm}^{-1}$ corresponded to the $v_{3}$ asymmetric stretching of the carbonate group [11]. The peak at $\sim 1072 \mathrm{~cm}^{-1}$ was due to the $v_{1}$ symmetric stretching mode of the $\mathrm{CO}_{3}$ group [11] suggesting, thereby the formation of calcite. The minor peak $1650 \mathrm{~cm}^{-1}$ were due to the adsorption of the atmospheric $\mathrm{CO}_{2}$ and $\mathrm{C}=\mathrm{O}$ stretching, respectively [11]. The formation of a mixture of calcium hydroxide and calcite in $\mathrm{NCH}$ powders were confirmed from FTIR spectroscopy.

\section{Conclusion}

Hexagonal regular shaped layered nanostructured $\mathrm{Ca}(\mathrm{OH})_{2}$ powders were synthesized by a simple, inexpensive chemical precipitation technique at room temperature. In the present work these nanopowders were applied on mortar samples of heritage buildings to check the compatibility of the synthesized NCH powder. The compatibility of this nano powder has been checked with respect to micro structure, porosity thermal expansion co-efficient and nanomechanical behavior. The molecular interaction and calcium carbonate transformation were studied by FTIR. The FTIR spectrum of the synthesized powder showed the band characteristics of both calcium hydroxide and calcium carbonate. The presence of nano calcium hydroxide on the surface of the treated mortar sample was confirmed and the fast carbonation process was also observed from XRD analysis. FESEM and EDAX line profile analysis are performed on the treated mortar sample to evaluate the interaction between the nao calcium hydroxide treatments and the porosimetric system of the heritage mortar sample. FESEM images showed the partial filling of the pores in the treated mortar sample without occluding them. This was also supported by reduction of porosity in treated sample. It was also observed that thermal co-efficient and was decreasing after treatment of synthesized $\mathrm{NCH}$ powder which revealed that the mortar under goes shrinkage due to volume decrease of the nano $\mathrm{Ca}(\mathrm{OH})_{2}$ phase. The result of this study shows the potential of the calcium hydroxide nano powders as an effective restoration material for protection of heritage mortar structures.

Acknowledgements This work was supported by the CSIR Mission Mode Project (No. HCP0018) tenable at CSIR-CGCRI. The authors are grateful to Dr. K. Muraleedharan, Director, CSIR-Central Glass \& Ceramic Research Institute, Kolkata 700 032, India for his kind permission to publish this work. The authors also acknowledge the ASI for giving permission to collect sample pieces from Heritage Buildings.

\section{Compliance with ethical standards}

Conflict of interest The authors declare that they have no Conflict of interests.

\section{References}

1. Boynton RS (1980) Chemistry and technology of lime and limestone. Wiley, New York

2. Adroer M, Valero F, Poch M, Sola C (1994) A new procedure for water decarbonation process control. Ind Eng Chem Res 33:1501

3. Yan K, Chin T, Liang DT, Laursen K, Ong WY, Yao K, Tay JH (2003) Kinetic Study of Hydrated Lime Reaction with HC. Environ Sci Technol 37:2556

4. Foreman PC, Barnes IE (1990) A review of calcium hydroxide. Int Endod J 23:283-297

5. Murray PE, Hafez PE, Smith AJ, Cox CF (2002) Hierarchy of pulp capping and repair activities responsible for dentin bridge formation. Am J Dent 15:236

6. Al-Omary RA, Al-Naddaf M, Al Sekhaneh W (2018) Laboratory evaluation of nanolime consolidation of limestone structures in the roman site of Jerash, Jordan. Mediterr Archaeol Archaeometry 18:35-43

7. Ashurst J, Dimes FG (1998) Conservation of building and decorative stone. Butterworth-Heinemann series in conservation and museology. Butterworth-Heinemann, Oxford 
8. Elert K, Rodriguez-Navarro C, Sebastian Pardo E, Hansen E, Cazalla O (2002) Lime Mortars for the conservation of historic buildings. Stud Conserv 47:62-75

9. Taglieri G, Mondelli C, Daniele V, Pusceddu E, Scoccia G (2000) Synthesis, textural and structural properties of calcium hydroxide nanoparticles in hydro-alcoholic suspension. Adv Mater Phys Chem 4(2014):50-59

10. Foreman PC, Barnes IE (1990) A review of calcium hydroxide. Int Endod J 23:83-297

11. Navarro CR, Suzuki A, Agudo ER (2013) Alcohol dispersions of calcium hydroxide nanoparticles for stone conservation. Langmuir 29:11457-11470

12. Rodriguez-Blanco JD, Shaw S, Benning LG (2011) The kinetics and mechanisms of amorphous calcium carbonate (ACC) crystallization to calcite, via vaterite. Nanoscale 3:265-271

13. Khouzani MF, Chevrier DM, Güttlein P, Hauser K, Zhang P, Hedin N, Gebauera D (2015) Disordered amorphous calcium carbonate from direct precipitation. CrystEngComm 17:4842-4849

14. Patel JP, Xiang ZG, Hsu SL, Schoch AB, Carleen SA, Matsumoto D (2015) Path to achieving molecular dispersion in a dense reactive mixture. J Polym Sci Part B Polym Phys 53:1519-1526

15. Salvadori $B$, Dei $L$ (2001) Synthesis of $\mathrm{Ca}(\mathrm{OH})_{2}$ nanoparticles from diols. Langmuir 17:2371-2374

16. Liu T, Zhu Y, Zhang X, Zhang T, Zhang T, Li X (2010) Synthesis and characterization of calcium hydroxide nanoparticles by hydrogen plasma-metal reaction method. Mater Lett 64:2575-2577

17. Roy $A$, Bhattacharya J (2010) Synthesis of $\mathrm{Ca}(\mathrm{OH})_{2}$ nanoparticles by wet chemical method. Micro Nano Lett 5:131-134

18. Daniele V, Taglieri G (2012) Synthesis of $\mathrm{Ca}(\mathrm{OH})_{2}$ nanoparticles with the addition of triton $\mathrm{X}-100$. Protective treatments on natural stones: preliminary results. J Cult Herit 13:40-46

19. Vojtěchovský J (2017) Surface consolidation of wall paintings using lime nano-suspensions. Acta Polytech 57:139-148

20. Das PS, Bhattacharya M, Chanda DK, Dalui S, Acharya S, Ghosh S, Mukhopadhyay AK (2016) Failure and deformation mechanisms at macro- and nano-scales of alkali activated clay. J Phys D Appl Phys 49:235503-235524

21. Rietveld HM (1969) A profile refinement method for nuclear and magnetic structures. J Appl Crystallogr 2:65-71
22. Kumar L, Kumar P, Narayan A, Kar M (2013) Rietveld analysis of XRD patterns of different sizes of nanocrystalline cobalt ferrite. Int Nano Lett 3(8):12

23. Waje SB, Hashim M, Yusoof WDW, Abbas Z (2010) X-ray diffraction studies on crystallite size evolution of $\mathrm{CoFe} 2 \mathrm{O} 4$ nanoparticles prepared using mechanical alloying and sintering. Appl Surf Sci 256:3122-3127

24. Merta I, Tschegg EK (2013) Fracture energy of natural fibre reinforced concrete. Constr Build Mater 40:991-997

25. Oliver WC, Pharr GM (2004) Measurement of hardness and elastic modulus by instrumented indentation: advances in understanding and refinements to methodology. J Mater Res 19:3-20

26. Dey A, Mukhopadhyay AK (2014) Nanoindentation of brittle solids, 1st edn. CRC Press, Boca Raton

27. Pelisser F, Gleize PJP, Mikowski A (2012) Effect of the $\mathrm{Ca} / \mathrm{Si}$ molar ratio on the micro/nanomechanical properties of synthetic $\mathrm{C}-\mathrm{S}-\mathrm{H}$ measured by nanoindentation. J Phys Chem C 116:17219-17227

28. Sing KSW, Everett DH, Haul RAW, Moscou L, Pierotti RA, Rouquerol J, Siemieniewska T (1985) Reporting physisorption data for gas/solid systems with special reference to the determination of surface area and porosity. Pure Appl Chem 57:603-619

29. Chanda DK, Chowdhury SR, Bhattacharya M, Mandal AK, Dey N, Mukhopadhyay AK (2018) Intelligently designed fly-ash based hybrid composites with very high hardness and Young's modulus. Constr Build Mater 158:516-534

30. Otero J, Starinieri V, Charola AE (2019) Influence of substrate pore structure and nanolime particle size on the effectiveness of nanolime treatments. Constr Build Mater 209:701-708

31. Vagenas NV, Gatsouli A, Kontoyannis CG (2003) Quantitative analysis of synthetic calcium carbonate polymorphs using FT-IR spectroscopy. Talanta 59:831-836

Publisher's Note Springer Nature remains neutral with regard to jurisdictional claims in published maps and institutional affiliations. 